\title{
THE RANKING OF DIMENSIONS FOR PROJECT-MANAGEMENT EFFICIENCY IN THE PUBLIC SECTOR
}

\author{
Hardus van $\mathrm{Zyl}$ \\ University of Johannesburg \\ hardusvz@uj.ac.za
}

February 2007

\begin{abstract}
The aim of the article is to introduce a project-management efficiency model in order to rank the dimensions of efficient project management in the public sector.

There is a need to develop and introduce measurement instruments that would enable decision-makers to prioritise the important dimensions of efficient project management. The results of the model will also demonstrate how project management acts as the primary function to enhance organisational performance, codified through improved logical endstate programmes, work ethics and process contributions.

The efficiency model/instrument that was developed can act as a tool to enable project managers to determine the important dimensions of efficient project management in their specific organisations.

A greater level of efficiency can be achieved if the organisation can work more efficiently and provide more effective services. The introduction of efficient project-management practices for an organisation is of the utmost importance in helping the organisation to fundamentally adapt to external threats to its existence and focus its endeavours in a coordinated manner.
\end{abstract}

\section{Keywords:}

DPE (Department of Public Enterprises), project management efficiency, efficiency model, power function, elasticity coefficients, survey questionnaire, data series. 


\section{INTRODUCTION AND PURPOSE}

The aim of the paper is to introduce an efficiency model in order to rank the important dimensions for efficient project management in the public sector. The Department of Public Enterprises (hereafter referred to as DPE) was used as a case study.

"Project management in a project-driven organisation is becoming more and more visible and more and more money is being spent to support the discipline of project management. Like you, top management is going to start asking where this money is going and what they are getting out of it. We'd better be ready to answer" (Knutson, 2001:456).

There is an assumption that the average citizen and shareholder expect to receive more in terms of the delivery of services and products for less money. This desirable outcome can only be achieved if the organisation works more efficiently and provides more effective services and products at a lower cost to its citizens. To be able to deliver these improved services and products at lower cost, it is required that an organisation implement its integrated strategic development plan and the programmes attached thereto through a clearly defined project-management approach. In short, projects must add value.

\section{LITERATURE STUDY}

A literature study was performed in order to identify possible dimensions of efficient project management that could be included as independent variables in an efficiency model. There are numerous publications that deal with various aspects of this topic. The author has decided to concentrate on the work done by Crawford (2003), Frame (2002), Knutson (2001), Breiner, Geldes and Hastings (1990), Gray and Larson (2003), Archibald (2003) and Kerzner (2001). The following dimensions were identified as independent variables that can be included in an efficiency model.

\subsection{Structural organisational support for project management}

Structural organisational support for project management can best be described as the focus on sufficient supportive structures, procedures and capacity. In this regard the types of organisational structures for project management are of paramount importance (Crawford, 2003:ii).

Knutson (2001:400-402) states that three possible project-departmental structures are envisaged on a continuum from less project-orientated to more project-orientated. At the start of the continuum is the classic functional or hierarchical structure in which the operating department undertakes a project that has boundaries within that functional area. This structure has limiting constraints and the employment thereof depends on size, complexity and multi-functional inputs that are required. As an organisation moves from a transactional orientation to a project orientation, it becomes necessary to involve various subject-matter experts from different functional areas. A project team is formed to accomplish a specific business objective. This is called a matrix structure. However, the 
commitment of the project team members in a matrix team is part-time. When project team members, and possibly the managers of the project, are moving between project responsibilities and the operational responsibilities of their functional unit, they may not be totally productive in either effort. At the other end of the continuum is a pure project structure. The managers of projects and the project team members are dedicated to the project full-time. The pure project team may be located in one place so that they can communicate more easily. Their effort then becomes more dedicated and their productivity is higher.

Knutson (2001:403) states that the choice of the appropriate operational structure depends on the type of project. Developing a proposal might best be served by a dedicated task force (pure project approach), whereas designing and implementing software products might successfully employ the matrix structure, in which different subject-matter experts are drawn from different functional groups. Different structures might be utilised during various phases of a project. For example, a functional or traditional hierarchical departmental structure might best serve the design phase (depending on the complexity of the design), but the development effort may achieve its best results by using a matrix with a centralised project office to coordinate the effort.

\subsection{Project-management methodology and project goals}

Project-management methodology and the setting of project goals refer to the way in which projects and programmes are measured, managed and communicated.

A portfolio is defined as a set of projects within an organisation, related to a specified frame that needs to be co-managed, whether they are interconnected or autonomous. A rigorous project-priority system is used to select which projects will be budgeted for and staffed in the organisation (Gray and Larson, 2003:33). Three different kinds of projects that can be found in an organisation's portfolio are: i) compliance and emergency projects (must do), ii) operational projects (daily, routine projects needed to support current operations) and iii) strategic projects.

Gray and Larson (2003:43) also state that, using the portfolio management system in an organisation, projects are assessed within the context of existing projects. Two major inputs are required from management in this process. First, senior leadership (from the organisation) must provide guidance in establishing and defining selection criteria of projects that strongly align with the current organisational strategies. Second, senior management must decide how they wish to bring equilibrium to available organisational resources among the different projects.

According to Knutson (2001:188) portfolio management restores manageability of projects by providing an organisation with an evaluation method that can be applied objectively to each proposed project. Every project must be properly scoped, planned and managed for the organisation to implement successful portfolio management. Projects are major investments for most organisations. Investments must be managed on a portfolio basis (Archibald, 2003:11).

Multiple projects can form a program with a single business objective. All individual projects, many of which interface with each other, contribute to this program. These related 
projects could be managed with relative ease in the project-management environment. However, if the project manager has to manage multiple unrelated projects, the effort becomes much more complicated and difficult (Kerzner, 2001:16).

Factors that make the management of multiple projects different to that of a single project need to be spelled out. With single projects there is one single objective to reach, one to-do list, a focussed work-breakdown structure and a defined resource pool to draw from. In a multiple-project environment where each project has its own objective, the situation is totally different. Resources come from all over and require different functions in the organisation (this is true of a single project also) (Frame, 2002:7).

\subsection{The human resources component of project management}

The adequacy of human resources and the effective learning and authority structures can best be described in the manner in which project teams operate and how well the projectmanagement office is staffed.

A project team is often a varying body of people from different levels of the organisation. Many of them may never meet each other (a virtual team). An organisational team describes this type of collaboration. Breiner et al. (1990:7) define the project team and stakeholders as: "All those individuals who have a significant contribution to make to the successful achievement of the project through one or more of $i$ ) their technical or specialist expertise ii) their sponsorship, political support or commitment and ii) their expectations of and interest in its outcome.

To create a sense of teamwork among people who previously did not even know each other, each with their own speciality, is a very difficult and complex task. The project leader needs to build a committed project group to achieve the full benefits, both personally and to the organisation, by cross-functional collaboration. Departmental teamwork (Breiner et al. 1990:9) incorporates three dimensions in the project leader's role, namely i) management of stakeholders in the project ii) management of the project life cycle and iii) management of the performance of individuals.

Knutson (2001:431) refers to the project-management office as an autonomous group that provides project-management support services. This group should be viewed as a service to be shared by all functions within the organisation. The job of this group is focused on the discipline of project management.

According to Crawford (2002:10) the project-management office makes the lives of project team members easier by supporting the team in the areas of, inter alia, scheduling, status reporting, project tool operation and training. Some of the key items of support provided by the project-management office include consulting and mentoring of current staff, developing and promulgating methodologies and standards relating to project management, and servicing as the central source for help in planning and managing efforts. The project-management office facilitates the improvement in project-management maturity by being the focal point for consistent application of processes and methodologies. Without a project-management office the project-management efforts of the organisation may not consistent and focused on a common vision. 
The project-management office is the proverbial glue that holds the project-management efforts of the organisation together.

\section{PROJECT-MANAGEMENT EFFICIENCY MODEL}

\subsection{Data}

An interview questionnaire was developed in order to capture the required data. The questionnaire was designed for simplicity of response in order to capture the greatest level of accuracy in the shortest possible time. The answers were divided into interval ranges as opposed to point estimators. This greatly simplified the interview process and reduced subjective interpretation to a bare minimum. The survey was divided into dispersed or scattered groups focused independently on each of the dimensions that make up the model of project-management efficiency. Each dimension was laid out in order to create a degree of continuity from statement to statement. The questionnaire contained forty statements that were divided into six different dimensions (see annexure A). The statements were taken from project-management literature (as discussed in the literature study) and interviews with project managers/coordinators and project team members within the DPE. The questionnaire was sent to thirty-five existing project managers and project team members within the DPE. In order to circumvent any possibility of a biased sample the respondents were chosen in such a manner that a representative sample group for each of the functions were included in the survey. The different functions of respondents were divided into the following areas, namely i) functional full-time manager/coordinator ii) part-time project manager/coordinator and iii) project team member. The respondents were requested to indicate on a scale of 1-5 the importance in their opinion of each statement in attaining a high level of efficiency in project management (see annexure A). Data series of the different dimensions were constructed.

The survey was also designed to facilitate the conversion of responses into data points in order to transfer them easily into a database and then interpret them with the assistance of a statistical package called SPSS version 11 for Windows. In terms of the SPSS package the data results were tested by way of the Kaiser-Meyer-Olkin measure of sampling adequacy and the establishment of a covariance matrix in which a reliability analysis could be performed.

The univariate properties of the data were also tested. The ADF test, Phillips-Perron test and correlogram tests were used to test for stationarity and the level of integration of each of the variables in the regression. The tests were performed on the data in their logarithmic form. From the ADF and Phillips-Perron tests it has been determined that all the variables were integrated in the order of 1 .

\subsection{The Model}

A power function was specified in order to determine the average elasticity coefficients of the six efficiency dimensions (independent variables). The average elasticity would indicate the relative magnitude of the impact of a specific dimension on the efficiency of project management. 


$$
\mathrm{U}=a\left(\mathrm{Cat}_{1}{ }^{b}\right)\left(\mathrm{Cat}_{2}{ }^{\mathrm{c}}\right)\left(\mathrm{Cat}_{3}{ }^{\mathrm{d}}\right)\left(\mathrm{Cat}_{4}{ }^{e}\right)\left(\mathrm{Cat}_{5}{ }^{f}\right)\left(\mathrm{Cat}_{6}{ }^{g}\right)
$$

(where $\mathrm{U}$ is the efficiency variable, Cat ${ }_{1}$ represents project goal clarity, Cat ${ }_{2}$ represents appropriate project-management methodology, Cat ${ }_{3}$ represents effective learning and authority structure, $\mathrm{Cat}_{4}$ represents access to the resources needed to execute projects, $\mathrm{Cat}_{5}$ represents organisational support for project management and Cat $_{6}$ represents the adequacy of human resources).

The power function was transformed into a double log equation which is linear in logarithms and was then run on the log of the variables.

$$
\text { In } \mathrm{U}=\text { In } a+b \text { In } \mathrm{Cat}_{1}+c \text { In Cat } 2+d \text { In } \mathrm{Cat}_{3}+e \text { In } \mathrm{Cat}_{4}+f \text { In } \mathrm{Cat}_{5}+\mathrm{g} \mathrm{In} \mathrm{Cat}_{6}
$$

The estimation results were:

$$
\mathrm{U}=\begin{array}{lllll}
\left.\begin{array}{l}
12.25\left(\mathrm{Cat}_{1}^{3.72}\right)\left(\mathrm{Cat}_{2}{ }^{2.25}\right)\left(\mathrm{Cat}_{3}{ }^{2.64}\right)\left(\mathrm{Cat}_{4}{ }^{6.74}\right)\left(\mathrm{Cat}_{5}{ }^{8.44}\right)\left(\mathrm{Cat}_{6}{ }^{6.11}\right)
\end{array}\right) \\
\begin{array}{llllll}
(3.1) & (2.75) & (3.98) & (2.87) & (2.88) & (2.68)
\end{array}
\end{array}
$$

Number of observations: 35

$R^{2}: 0.91$

F-statistic: 188.24

D-W: 3.38

The good overall explanatory power of the entire regression is indicated by high $R^{2}$ and F-statistic values and all the t-statistics of estimated parameters exhibit explanatory power.

Econometric tests were conducted to determine any traces of autocorrelation and heteroscedasticity. The $D-W$ statistic exceeded $d_{u}$, which clearly indicates no autocorrelation. The ARCH test conducted indicates no heteroscedasticity present in the error terms. Therefore, the estimators are asymptotically efficient. The error terms were not serially correlated and it can be stated that all the explanatory variables have been included in the equation.

The positive signs of the estimated average elasticity coefficients have indicated a positive relation between the six different dimensions of project management and the attainment of project-management efficiency. The estimated results confirm what would normally be expected, namely that organisational support for project management (an elasticity coefficient of 8.44 ), access to resources needed to execute projects (an elasticity coefficient of 6.74) and adequacy of human resources (an elasticity coefficient of 6.11) have a marked impact on the efficiency of project management.

The other three dimensions of project management (project goal clarity with an elasticity coefficient of 3.72, effective learning and authority structure with an elasticity coefficient of 2.64 and, finally, appropriate project-management methodology with an elasticity 
coefficient of 2.25) had far less of an impact on project-management efficiency.

\section{MANAGEMENT IMPLICATIONS}

From the results of the model it can be deduced that several mechanisms will be required to address the outcomes highlighted by the questionnaire. These are i) implementation of proper change-management ii) relevant process changes iii) appropriate leadership to bring about change iv) organisational culture changes to accept project-management methodology within the organisation v) a project management strategy vi) appropriate systems and vii) organisational changes to accommodate project management into the organisation's structure.

In order for the organisation to be able to manage projects across functions, it will have to start operating as a matrix-structured organisation. Implementing this type of structure can enable the successful completion of projects across functions and will assist the organisation to do more with less. The process of establishing a project-management methodology can be supported by a central project-management office (to facilitate and give authority to project decision-making), headed by a professional project manager who has sufficient authority within the organisation. The central project-management office can support decentralised project management offices in areas such as systems, procedures, policies and infrastructure to ensure uniform standards and practices throughout the organisation. It can also take responsibility for project-management training in the organisation.

The whole process of changing from a functional to a matrix department is a complex one. Knutson (2001:437) elegantly states that one must "Recognise that this is a significant cultural change. The transition needs to be orchestrated and roles, accountabilities and authorities clearly defined and communicated". Any recommendation to move towards the achievement of optimal project management in the organisation must be supported by top management.

An adequate budget and sufficient resources must be made available to ensure the successful implementation of a project-management methodology within the organisation.

\section{CONCLUSION}

The article presented an efficiency model that can rank important drivers for project management efficiency. It is a tool that can be implemented by decision-makers to determine the relative importance of the dimensions of efficient project management in their specific organisations and to enhance greater project management efficiency.

A greater level of efficiency can be achieved if the organisation can work more efficiently and provide more effective services. Therefore, the author is of the opinion that efficient project management practices for an organisation is of great importance in assisting the organisation to fundamentally adapt to external threats to its existence and focus its endeavours in a coordinated manner. 
Hvan Zyl

\section{REFERENCES}

Archibald, R.D. (2003). Managing High-Technology Programmes and Project. $3^{\text {rd }}$ Edition. Hoboken: John Wiley \& Sons, Inc.

Breiner, W., Geddes, M \& Hastings, C. (1990). Project Leadership. New York: Van Nostrand Reinhold.

Crawford, J.K. (2002). Project Management Maturity Model. New York: Marcel Dekker AG.

Frame, J.D. (2002). The New Project Management. $2^{\text {nd }}$ Edition. San Francisco: Jossey-Bass, Inc.

Gray, C.F. \& Larson, E.W. (2003). Project Management: The Managerial Process. New York: McGraw-Hill.

Kerzner, H. (2001). Strategic Planning for Project Management using a Project Management Maturity Model. New York: John Wiley \& Sons, Inc.

Knutson, J. (2001). Succeeding in Project-Driven Organisations. New York: John Wiley \& Sons, Inc. 


\section{Annexure A}

Dimensions of project management efficiency

Using the following 5 -point scale, indicate in a range between 1 and 5 which of the following best describes your attitude towards the listed statements on project management.

\begin{tabular}{ccccc}
\hline $\begin{array}{c}\text { Not important at } \\
\text { all }\end{array}$ & $\begin{array}{c}\text { Limited } \\
\text { contribution }\end{array}$ & Neutral & Important & Very important \\
\hline 1 & 2 & 3 & 4 & 5 \\
\hline
\end{tabular}

The different categories and statements are listed in the following set of tables.

\section{Category 1: Project-goal clarity and alignment}

This category makes reference to the extent to which project goals are clearly defined upfront, are articulated to project participants and generally attained the commitment of participants.

\section{Statements}

1. Clear project goals and objectives are set up at the outset for the completion of our projects.

2. Project managers and project team members know what is expected of them.

3. The outcome expected of each project is clear to all stakeholders.

4. Projects are grouped within programmes to achieve common goals.

5. Once determined, project goal posts are not moved in the organisation.

6. The goal of our projects is to act as the facilitators for the upliftment of our communities.

7. The organisation's project priorities align with organisational priorities. 
Category 2: Appropriate project-management methodology

This category describes the degree to which the organisation follows a standardised and formal methodology of project management with appropriate systems and processes.

\section{Statements}

8. Projects across the organisation are measured on a standardised basis against performance achievement.

9. Projects across the organisation are measured on a standardised basis against time.

10. Projects across the organisation are measured on a standardised basis against budget.

11. Standardised project-management methodology supports the successful completion of projects within the organisation.

12. Project managers execute their projects in a disciplined and structured manner.

\section{Category 3: Effective learning and authority structure}

This category describes the extent to which there are effective ways of organising project teams, assigning project responsibilities and delegating authority to make decisions.

\section{Statements}

13. Project managers do have the authority to execute their projects.

14. Project managers are able to learn from other, similar projects.

15. Natural competitiveness of project managers is used to improve performance.

16. Project managers have full control of their projects.

17. Project managers are held responsible for their project-management success.

18. Project managers can execute their projects effectively due to minimum bureaucratic systems in the department.

\section{Category 4: Access to the resources needed to execute projects}

This category describes the degree to which project managers can rely on a strong enough resource platforms and/or support base, and can adequately access and manage the assigned resources

\section{Statements}

19. The organisation has sufficient capacity to complete projects successfully.

20. The potential of project managers is utilised fully. 
Category 5: Organisational support

This describes the extent to which top management and the entire organisation understand and support the project-management function.

\section{Category 6: Adequacy of human resources}

This category describes the extent to which people assigned to projects are generally competent in their line of specialisation and display sufficient commitment to delivering quality work.

\section{Statements}

35. The performance of a project manager is measured.

36. The organisation allows for project managers to take initiative.

37. Project managers are trained sufficiently to be competent project leaders.

38. People who train project managers in the organisation are sufficiently skilled in project-management practices.

39. Project team members have adequate project-management-related skills.

40. Project managers have sufficient problem-solving abilities.

Source: Adapted from the literature study 
